\title{
JUSTICIA Y POLÍTICA EN LA ESPAÑA DEMOCRÁTICA (Una reflexión a propósito de los llamados ujueces estrella» y la judicialización de la política)
}

\author{
GREGORIO CÁMARA VILLAR \\ Catedrático de Derecho Constitucional \\ Universidad de Granada
}





\title{
JUSTICIA Y POLÍTICA \\ EN LA ESPAÑA DEMOCRÁTICA (Una reflexión a propósito de los llamados "jueces estrella» y la judicialización de la política) ${ }^{1}$
}

POR

\author{
GREGORIO CÁMARA VILLAR \\ Catedrático de Derecho Constitucional \\ Universidad de Granada
}

«El más clásico de los contrapoderes, los medios de comunicación, se ha convertido en el cuarto poder, y a veces juega incluso a ser el primero. El derecho planea por encima de la sociedad y el juez, su brazo secular, se alió con la opinión pública y con los medios de comunicación".

Alain Minc. La borrachera democrática.

I.

En los últimos diez o quince años el papel del juez en la vida política de la sociedad democrática, sobre todo en los países del conti-

1 Este texto, que sirvió de base a la conferencia pronunciada en el curso "EI poder judicial a debate", organizado en Ávila por la UNED en julio de 1998, es la contribución del autor al Libro Homenaje al Prf. JoAQuín GARCiA MoRILLO, en curso de publicación. 
nente europeo, ha crecido espectacularmente. El protagonismo del Derecho y del poder judicial en este final de siglo y de milenio es un fenómeno inquietante porque apunta a movimientos profundos de transformación de la democracia que apenas se intuyen y que se resisten, por su gran complejidad, al análisis. La misma realidad del fenómeno aparece en este supuesto altamente contradictoria: se reivindica la justicia material, pero se adopta como paradigma el rigor técnico de un Derecho entendido como procedimiento de última apelación para la resolución de los problemas sociales y políticos; las demandas de tal clase, incluso de manera explícita o implícita las de índole moral, se dirigen cada vez más directa y masivamente a la justicia, pero se repudia el activismo judicial; la Administración de justicia se percibe negativamente y con grandes carencias por el conjunto de la población, pero al mismo tiempo se depositan en ella todas las esperanzas como última garantía del Estado democrático ante una crisis política de fondo; se cuestiona la legitimidad democrática del juez, pero este aparece en el imaginario colectivo, en el marco de una imperfecta democracia cada vez más deficitaria en su legitimidad de ejercicio, como la ulterior instancia definidora del bien y del mal, de lo justo y de lo injusto; los jueces y tribunales (también la actuación del Ministerio fiscal) son, junto con los medios de comunicación, lós réferentes casi exclusivos para el control de la vida pública y de los actos del poder, pero a su vez no queda más remedio que plantearse recurrente y circularmente la cuestión de quién controla a estos controladores.

La reflexión sobre la multiplicidad de aspectos y factores conformadores de esta realidad (en este caso referida al caso español), no puede llevarse a cabo ni exclusiva ni prioritariamente de la mano de la exégesis de las normas constitucionales y legales. Como constitucionalista me sería más grato apegarme a ellas y encontrar así el amparo. de un espacio académico más claro y seguro, aún a riesgo de situarme en una ya trillada (por importante que pueda ser) descripción sobre la justicia constitucionalizada $y$, eventualmente, en una discusión sobre valores y principios constitucionales. Pero puesto que me dirijo, en el marco de este curso, a expertos juristas, creo que puedo permitirme orillar estos aspectos o darlos por sobreentendidos y plantear la cuestión en otro plano y con la dosis de impresionismo, interdisciplinaridad e incluso de impureza metodológica que requieren las primeras aproximaciones a la discusión de temas de tanta trascendencia y complejidad política, con el objetivo de argumentar -como decía Juan J. RuizRico- no jurídicamente, sino para el conocimiento del sistema jurídico, $y$ aún a riesgo de no llegar a ningún nuevo puerto. $Y$ la reflexión no puede sino partir del reconocimiento de los rasgos definitorios y evo- 
lutivos de la sociedad democrática en el seno de la cual se proyecta hoy la actuación del juez y de la justicia.

Cuando hablamos del papel del juez en una sociedad democrática, nos referimos a una sociedad democrática avanzada regida, no lo olvidemos, por una Constitución normativa presidida, entre otros, precisamente por el valor justicia y profundamente concernida con la tensión por hacer realidad, en plenitud de efectividad, los principios y requerimientos del Estado social y democrático de Derecho. Una sociedad sometida a grandes tensiones y a profundos y cada vez más acelerados - cambios como consecuencia de los procesos de mundialización de la información, de la economía y de la política y forzosamente ensimismada en sus propias capacidades de desarrollo, cambio y reequilibrio por la inexistencia de alternativas históricas tras la caída del comunismo. Una sociedad que bulle atrapada entre, de un lado, las contradicciones y tensiones que provoca el paradigma teórico/práctico del Estado del bienestar $y$, de otro, los procesos de mercantilización y de transferencia de poder del Estado a administraciones autónomas y a grupos privados. Una sociedad fuertemente castigada por la aparición de fenómenos muy complejos de crisis y deslegitimación de la clase política y del poder del Estado derivados de recurrentes episodios de corrupción y de otros enmarcados en la lucha contraterrorista, con importantes puntos de conexión entre sí. Una sociedad en la que el pueblo ya no es concebido como un colectivo homogéneo, ni el Parlamento es tenido por el exclusivo e ilimitado representante del pueblo soberano. Una sociedad postindustrial y al extremo pluralista donde la ley entra en crisis porque envejece rápidamente $y$, como exigencia de la orientación y conformación política, se hace necesaria su expresión singular y en la que, por tanto, la vertiente jurisdiccional y creativa del Derecho adquiere cada vez mayor importancia, hasta el punto de que la jurisdicción se convierte, de hecho, en un centro más de producción normativa. Una sociedad en la que el necesario intervencionismo del poder público y su función promocional produce una acusadísima preeminencia del ejecutivo y una ingente actividad de la Administración, creando situaciones y actuaciones potencialmente lesionadoras de derechos de los ciudadanos. Una sociedad en la que el protagonismo político ha venido siendo asumido por los partidos como grandes maquinarias electorales $y$, en realidad, como sujetos colectivos de representación que, en buena medida, han apartado al ciudadano de su directa implicación en el sistema democrático. Una sociedad en la que se está produciendo una profunda quiebra de la centralidad del Parlamento y, por tanto, donde se ve alterada su función de institución idónea para la confrontación política entre poder y oposición, para la negociación entre mayoría y minoría, 
donde deben llegar agregados los planteamientos de los conflictos sociales e institucionales subyacentes, ser articuladas las soluciones políticas y deducidas, en su caso, las responsabilidades políticas. Una sociedad que, en otra perspectiva, ha potenciado una extraordinaria dimensión activa (si bien con alto riesgo de ser en buena medida populista) del ciudadano, hoy exigente postulante de sus derechos e informado delator de las contradicciones -aparentes y reales- entre las proclamaciones constitucionales y la realidad. Una sociedad en cuyo centro se ha instalado un nuevo, paradójico pero imprescindible contrapoder, el llamado "poder mediático", capaz de nutrirla con los más efectivos elementos democráticos de crítica y de exigencía de responsabilidad política difusa al poder y a los poderosos, pero también actor político con intereses autónomos -los de la influyente élite que lo compone-, capaz por todo ello de poner en repliegue -y hasta en jaque- a los poderes del Estado. Una sociedad preocupada por la judicialización progresiva de la política y por la que se entiende correspondiente e inevitable politización de, al menos, una parte de la justicia. Una sociedad, en fin, en la que muchos viejos mitos polfficos, al menos con sus ropajes clásicos, se ven puestos en cuestión precisamente cuando las posibilidades de profundización democrática, debido a los avances técnicos y a los logros materiales, se ven multiplicadas.

En conclusión, asistimos a una permanente transformación de la sociedad y del universo simbólico democrático precisamente porque transitamos lentamente, como ya dijera Hermann Heller en los años treinta, desde "una democracia racional individualista a una democracia social indeterminada", todavía hoy indeterminada. Frente al espejismo de una democracia establecida conforme a cánones permanentes de racionalidad, es precisamente la idea de continuo cambio y reajuste la que debe reclamarse como consustancial a la democracia, sin que fuera de ésta pueda existir otra posible legitimación del poder. Es en el marco de esta sociedad, a la luz de sus tensiones, de sus contradicciones y de sus entrevistas proyecciones, donde debemos repensar, con el trasfondo de estos enunciados y anudados factores, la función del juez y de la justicia y valorar las expresiones concretas de su práctica. En el actual estadio del desarrollo democrático todo parece apuntar a que corresponde un especial protagonismo al poder judicial entendido en sentido amplio como poder de la jurisdicción, porque tras los logros de la libertad y de la igualdad en la ley alcanzados por la legislación y tras los logros del Estado asistencial y de bienestar propios de la conjunción legislativo-ejecutivo, se ha llegado a un momento en la evolución del constitucionalismo en el que lo que está en cuestión es la salvaguarda y protección de esos logros a través del sistema de ga- 
rantías que hace posible la normatividad de la Constitución, donde su quintaesencia ha quedado prendida como contenido inexcusable del paradigma de la sociedad democrática avanzada que sostiene, tras siglos de evolución, la "cultura occidental» actual. En este sentido puede gráficamente decirse, como tantas veces se ha repetido, que si el siglo XIX fue el siglo del legislativo y la primera parte del XX del ejecutivo, en la segunda parte del $X X$ nos hemos situado en el del poder judicial.

II.

Soy consciente de la "todo-abarcante" $-y$, por ello, excesiva-capacidad de evocación que tienen tanto el título de esta ponencia como la entrada en materia que acabo de hacer, en tanto que sugieren múltiples desarrollos tópicos en el ámbito académico y no menos abundantes temas de coyuntura. Asi, junto a ineludibles aspectos centrales, como serían la posición del poder judicial en el ámbito de la separación y colaboración de los poderes del Estado y, en correspondencia, la cuestión de cómo se hacen hoy por hoy operativas la imparcialidad, la independencia y la responsabilidad del juez, surgen posibles temas conexos de actualidad, algunos de ellos muy polémicos $y$ de una gran transcendencia política y jurídica como son, a modo de ejemplo, el control jurisdiccional de los actos políticos del gobierno y los secretos de Estado, la cuestión del gobierno del poder judicial, la definición del papel del Ministerio fiscal y la instrucción del sumario, por no citar otros no menos importantes como la selección y formación del personal judicial, el jurado, etc... Pero no es mi propósito echar sobre mis espaldas la pesada carga de "revisitar» tan impresionante catálogo temático, ni siquiera como mero apunte. Mi pretensión es mucho más modesta: me centraré en un tema que, pese a parecer episódico, en cierto modo reúne o implica buena parte de los conceptos y cuestiones que plantea el proceso de cambio que está viviendo la justicia en el seno de un Estado democrático no menos cambiante que la sociedad que rige, tema sobre el que existe una evidente carencia de investigación especializada, al menos en España: se trata de la cuestión del surgimiento y auge reciente de la figura de los llamados "jueces estrella»; "jueces políticos" o politizados por definición, los «jueces justicieros» o "jueces Superman" en la caricaturesca expresión hace no mucho empleada por el Presidente del Congreso de los Diputados, Sr. Trillo, en el debate sobre la Audiencia Nacional (Miguel Ángel Aguilar ha preferido llamar desde sus colaboraciones en los medios de comunicación a uno de ellos, con reiteración y grafismo, el "juez campeador»). 
La mención de este tipo de juez despierta, en efecto, la idea de una judicialización de la política y de una politización de la justicia y, con ello, la amenaza de una cierta quiebra del Estado de Derecho, la ruptura del equilibrio institucional y entre los poderes en el seno del Estado democrático, así como la pérdida de la racional moderación y seguridad que debe presidir su funcionamiento, como ya advirtieran en su época, entre otros, Montesquieu, Constant o Tocqueville. La sola referencia a algunos de los nombres asociados a esta imagen evoca, para algunos, la confirmación paradigmática, aunque como excepción en el conjunto del sistema, de una meritoria y esforzada independencia judicial coherente con la separación de poderes, practicada en dura lucha frente a la extralimitación de algún poder o institución del Estado, frente a los poderósos y sus seculares inmunidades. Para otros -si no estoy equivocado, la mayoría-, tal figura sugiere precisamente todo lo contrario, esto es, la evidencia de que se ha producido el salto hacia una nueva e ilegítima función política de la magistratura, una de las manifestaciones de la creciente asfixia de lo político por lo jurídico, el abrazo de hierro de la política por el Derecho, el más evidente fenómeno de activismo judicial intolerable. Intolerable porque se percibe como conducente a lo que de manera intuitiva e imprecisa se viene calificando, generalizando el panorama, como "gobierno" o "república de los jueces", o "Estado de la justicia judicial", fenómeno valorado a su vez como expresión parcial de un proceso mucho más vasto y lento que se identifica como crisis del Estado. La referencia inmediata, tanto para lo bueno como para lo malo, no puede dejar de ser sino Italia y el movimiento conocido como Mani Pulite (aunque en realidad implementado por fiscales), así como Francia (la révolte du petit juge), aunque muchos acontecimientos parecidos al español se estén dando también en otros países europeos como Bélgica, Holanda, Portugal, Alemania (en menor medida) y también en otros lugares como en Japón, si bien cada caso presenta sus específicas características y ninguno es enteramente asimilable a otro, salvo en el desequilibrio ( $y$, a veces, en el caos) institucional que generan.

III.

No se me antoja mala idea, para apreciar la dimensión de la cuestión en su dinámica histórica en España, echar una ojeada al pasado y observar el cambio de escenario en el que nos movemos, partir del recuerdo de cuan diferente índole eran los problemas que planteaba la justicia a la naciente democracia española. Tras situar en su frontispi- 
cio la afirmación del valor justicia, la Constitución española asumía que "la justicia emana del pueblo y se administra en nombre del Rey por Jueces y Magistrados integrantes del Poder Judicial, independientes, inamovibles, responsables y sometidos únicamente al imperio de la Ley", a quienes corresponde "exclusivamente el ejercicio de la potestad jurisdiccional en todo tipo de procesos, juzgando y haciendo ejecutar lo juzgado y sin que puedan ejercer más funciones que las señaladas anteriormente y expresamente atribuidas por la Ley en garantia del cualquier derecho", remitiendo a la determinación de la Ley Orgánica del Poder Judicial la constitución, funcionamiento y gobierno de los Juzgados y Tribunales, así como el estatuto jurídico de los Jueces y Magistrados de carrera y del Consejo General del Poder Judicial como su órgano de gobierno (arts. 117 y 122). El juez que la Constitución quiere es, en definitiva, un juez independiente, responsable y sujeto únicamente al imperio de la ley, no un juez sumiso, dependiente y burócrata. La Constitución depositó su confianza en el Poder judicial, del que son portadores todos los jueces uti singuli, para -por decirlo con las palabras certeras de Bachof al referirse muchos años antes a la Ley Fundamental de Bonn-, "restablecer y afirmar la quebrantada creencia en la soberanía del Derecho y en la posibilidad de un imperio del Derecho; la creencia de un Derecho al que están sometidos no sólo los ciudadanos, sino también el Estado: el Derecho como medida del poder".

Pues bien, al comienzo de nuestra andadura constitucional e incluso todavía bien entrada la segunda mitad del pasado decenio, los problemas de la justicia en España eran, fundamentalmente, por un lado, el de la ausencia de conciencia constitucional y democrática de los jueces $y$, por otro -unido al anterior a través del cordón umbilical que supone la méfiance histórica que sobre ellos pesa, agigantada por la instrumentación que del poder judicial hizo el franquismo-, la polémica de alcance constitucional sobre la configuración del órgano de autogobierno de la magistratura, el Consejo General del Poder Judicial. Creo que sin gran esfuerzo podemos acordarnos de la prevaleciente imagen social de fondo de una magistratura mayoritariamente antidemocrática, proclive a la inobservancia de la Constitución, incluso deliberadamente resistente al cambio político. Se conformó así un estereotipo de los jueces españoles, vigente hasta la segunda mitad de la década, en buena parte alimentado por los medios de comunicación, que llegó a alcanzar su más extrema y difusa versión entre los componentes de la propia élite jurídica, incluidos los propios jueces, que se concibieron a sí mismos como miembros de un colectivo profundamente conservador, como acreditaron diversos estudios (entre 
otros, el realizado por un equipo investigador dirigido por el prof. Ruiz-Rico).

Los medios de comunicación que asumieron las posiciones más críticas (EI País, Diario 16) transmitían la imagen de que el juez no respondía ideológicamente al modelo de Estado democrático por cuanto que se estimaba que eran los de antes, los de siempre, con las mismas ideas. Se daba por supuesto que la judicatura española, independientemente de los cambios habidos, incluso el generacional, era conservadora en extremo (si bien con el ropaje, a veces, del apoliciticismo y el profesionalismo). Tal ambiente impregnó intensamente el iter legislativo del Proyecto de Ley Orgánica del Poder Judicial. Véase como botón de muestra el siguiente diagnóstico periodístico de Pere Bonnin sobre la percepción de ese ambiente:

"Jueces y Magistrados, junto con los funcionarios que trabajan en la Administración de Justicia, se han convertido con el advenimiento de la democracia en cabezas de turco de un sistema judicial que no funciona. El ciudadano común, que vivió la frenética actividad de los oficiantes del Tribunal de Orden Público durante el franquismo, tiende a ver en el juez y el magistrado los residuos vivientes de la fenecida dictadura. Este espejismo es tanto más claro cuanto más dura fue la clandestinidad o el desasosiego de los ciudadanos que así piensan. Por eso han surgido latiguillos tales como "la mayoría de los jueces son golpistas", "los jueces son antidemócrata", "los jueces tienen que pasar por el tubo" y otros muchos propios de conversos intransigentes que pretenden repartir bendiciones y anatema democrático como quien reparte cacahuetes a los monos.»

En el Discurso de apertura del Año Judicial de 1983, Federico Carlos Sáinz de Robles, Presidente a la sazón del Tribunal Supremo y del Consejo General del Poder Judicial, se hacía eco de esta misma situación y acusaba a los medios de comunicación de ser los responsables de esta imagen tan negativa y distorsionada de la justicia, imagen que caracterizaba según estos cuatro grandes rasgos: «a) Predominio impresionante de cuanto atañe a la justicia penal (seguridad ciudadana, procesos a periodistas, los llamados procesos paralelos, etc...; b) Insistencia en la lentitud, carestía, esoterismo e ineficacia de la justicia; c) Dificultades que presentan simultáneamente la carencia de recursos y la obsolescencia de las normas procesales; y d) Valoración negativa, y a veces personalmente descalificadora, de los jueces, más que nada por su falta de idoneidad para un Estado democráticon.

Pudiera decirse que el así condensado catálogo de problemas no difiere mucho del balance que de la justicia podría hacerse en estos 
momentos. Y así es, en efecto, pues para probarlo bastaría tan sólo con consultar los más recientes sondeos de opinión. Relata José Juan Toharia cómo de los datos obtenidos del barómetro de primavera realizado por Demoscopia para «El País», publicado el 14-3-95, puede obtenerse una imagen percibida de la justicia como lenta, ineficaz, arbitraria, incoherente, discriminatoria con los acusados, abusiva en el uso de la prisión preventiva y depositaria de un poder excesivo. Por su parte, los resultados del Barómetro de opinión del Centro de Investigaciones Sociológicas realizado en diciembre de 1996, arrojan el balance de que la justicia es la institución menos valorada $(3,7$ puntos sobre 10$)$ hasta el extremo de ser suspendida, por debajo del Gobierno y del Tribunal Constitucional, siendo además mayoría quienes opinan que los tribunales funcionan muy mal, así como los que sostienen que los jueces carecen de independencia. $Y$ los barómetros de opinión que han ido sucediéndose desde entonces no arrojan un panorama muy distinto en este tema. No obstante -subrayo esta idea- hoy no podría sostenerse seriamente la reflexión del último punto del diagnóstico que realizaba Sáinz de Robles relativa a la creencia de que los jueces carecen de idoneidad para un Estado democrático. Ni es así, por supuesto, ni lo percibe así la ciudadanía. Es más, los resultados de los sondeos ofrecen en este punto una visión ambivalente de la justicia, pues la mayoría de los españoles la ve hoy, a pesar de hacerse eco de sus graves carencias y de las necesidades de reforma, como «la última garantía para la supervivencia del Estado democrático en el caso de una profunda crisis política". Algo verdaderamente llamativo que tiene mucho que ver con los cambios que se están operando en el sistema democrático.

Aquel estereotipo al que nos referíamos, ciertamente, ha dejado de tener vigencia. Pero, ¿se ajustaba entonces a la realidad? Incluso para aquellos tiempos, y creo que con razón, las investigaciones disponibles ponen claramente de relieve que no era así, al menos desde un punto de vista socio-psicológico, dándose la circunstancia de que la mayoría de los jueces españoles, desanimados y desmoralizados por la degradación que en la imagen social tenía la justicia, se autosituaban en posiciones de centro-izquierda desde el punto de vista ideológico, constituyendo abrumadora mayoría (el $86 \%$, según las investigaciones del prof. Ruiz-Rico) el conjunto de aquellos que consideraban la democracia preferible a cualquier otra forma de gobierno. Otros indicadores disponibles (conocimiento del instrumento de la cuestión de inconstitucionalidad y su empleo para evitar un endose demasiado automático al Tribunal Constitucional de las dudas sobre la inconstitucionalidad de una norma, la aplicación directa de la Constitución para entender derogadas leyes preconstitucionales, la interpretación de las normas confor- 
me a la Constitución, etc...) eran más que suficientes para poner en cuestión el prejuicio entonces circulante sobre la ausencia de sentimiento constitucional en buena parte de los jueces españoles e, incluso, la mera sospecha de autoritarismo insuperable heredado de su posición en el régimen franquista, sospecha con la que a veces se quisieron explicar carencias de la justicia que en realidad respondian a razones bien distintas de orden estructural: como ha subrayado Miguel Ángel Aparicio, la judicatura española jamás habia estado sometida a la Constitución, lo cual la ponía en una dificilísima situación ante la necesidad de interpretar $y$ aplicar un ordenamiento jurídico conforme a pautas constitucionales. Como conjunto orgánico, "apoliticismo, anticonstitucionalismo y antiestatalidad son parámetros no sólo ideológicos, sino también estructurales, de nuestra judicaturan.

Que aquello fuese así, esto es, que el estereotipo funcionase durante los primeros años de la democracia no era, pues, el resultado de un capricho de la población o de los líderes de opinión y los medios de comunicación: la formación del estereotipo se había venido fraguando sobre bases muy sólidas $y$, por ello, su credibilidad era todavía mayor, pese a que cambios radicales ya se habían producido o se venían produciendo sin que fueran del todo visibles en la superficie. El juez de la España franquista actuó, dentro de una dilatada tradición romano-canónica ya marcada por el conservadurismo y por el modo de entender su función como defensora del orden público, sin ninguna proyección creativa desde el punto de vista jurídico, como un autómata que pronuncia las palabras de la ley, sujeto en el mejor de los casos al más puro y funcional legalismo. $Y$ el régimen de Franco supo sacar partido a la Administración de justicia para sus necesidades represivas, agrupando, por una parte, a los jueces adictos en las jurisdicciones especiales y, por otra, favoreciendo la apariencia de neutralidad política de los jueces ordinarios, creando una imagen distorsionada de su profesionalidad, basada en un apoliticismo pregonado y en un concepto "sacral" y mistificado de su independencia frente a todo poder, frente a la sociedad e incluso frente a sí mismos.

La continuidad histórica y el cambio generacional se irian encargando de ir poniendo las cosas en su sitio, desvelándose progresivamente, por un lado, la falsedad del estereotipo y, por otro, la reacomodación de la magistratura a los criterios, exigencias y necesidades de una Constitución democrática y normativa, aunque, eso sí, tras ser poderosamente incentivada por el ambiente y los pronunciamientos y la doctrina del Tribunal Constitucional; pero sin que ello supusiera la plena desaparición del claro desajuste existente entre la práctica judicial en España y la función que a los jueces encomienda la Constitución. 
IV.

El Estado democrático, bajo el imperio de la Constitución normativa, ha potenciado extraordinariamente, como no podía ser de otra manera bajo estos presupuestos, la dimensión activa del juez -no, por supuesto, el activismo- al devolverle uti singuli (no sin ciertas contradicciones) su condición de portavoz de un poder del Estado, el poder de la jurisdicción, un poder que puede definirse como distinto, independiente, neutral o supra partes, únicamente sometido a la Constitución y a la Ley y, por ello, y sólo por ello, según el dictum de Montesquieu, invisible et en quelque façon nulle; un poder que asegura el imperio de la Ley desde la supremacía de la Constitución y que se ejerce para preservar la libertad y la seguridad de los ciudadanos según la definición que de ellas ha realizado la voluntad popular, pero sin poder precisarla, como tampoco el interés general, ya que le viene prescrito en la norma, pero por eso mismo con el poder terrible ("de todos los días, de todos los instantes") de ejecutar sus designios sin otro freno que provenga de cualquier otro poder.

Estamos, pues, ante un poder que, en la realidad actual del llamado "Estado de partidos", viene a expresar la posibilidad más real e intensa del vigente y viejo dogma, si bien teleológicamente reformulado, de la separación de poderes. Como entre tantos otros nos recordara Bachof, el liberalismo y, por tanto, el constitucionalismo primitivos depositaron toda su confianza en la ley y desconfiaban, sobre todo, del juez, servidor del príncipe en el absolutismo: la única manera de vincularle al nuevo sistema era convertirlo en servidor de la ley, en la boca que pronuncia las palabras de la ley. La ley, razón convertida en norma, era la garantía contra el abuso del poder y no había otro Derecho sino el de la ley. Tal es el origen del positivismo. Hoy el poder se concentra en la conjunción mayoría parlamentaria-gobierno, y la ley no es tanto razón convertida en norma cuanto decisión política orientada a un concreto fin, y tanto los derechos fundamentales de los ciudadanos como el Derecho objetivo, que ya no es sólo ni primero el que resulta de la ley, como se desprende de la supremacía de la Constitución democrática y normativa, han de ser garantizados en esta situación frente a potenciales abusos o desviaciones de estas fuentes de poder. En consecuencia, es el poder jurisdiccional, el poder de decir el Derecho aplicable a cualquier relación, el único susceptible de controlar al poder político efectivo, esto es, tanto al legislador, como al gobierno propiamente dicho y a la Administración. Repárese en que hablamos de poder jurisdiccional, y no sólo de poder judicial ordinario, por lo que en esta misma lógica se inscribe la jurisdicción constitucional, que no es 
poder judicial, y por ello aludimos al control de constitucionalidad de las leyes en esta línea de razonamientos atenida prioritariamente al poder judicial.

La proclamación constitucional del valor justicia como superior del ordenamiento, el sometimiento de los ciudadanos y de los poderes públicos a la Constitución, el sometimiento asimismo pleno de la Administración a la ley y al Derecho, la distinción Derecho-ley que circula implícita por todo el texto constitucional, el reforzamiento de los principios generales como generadores de normas, la asignación de una función promocional a los poderes públicos en relación a la libertad, la igualdad y el pluralismo, el papel de los jueces como intérpretes y garantes de la Constitución $y$, con particular intensidad, de los derechos $\mathrm{y}$ libertades fundamentales, etc..., son aspectos, entre otros muchos, que nos hablan claramente de esta realidad, sin que en este contexto podamos extendernos en su desarrollo pormenorizado. Lo importante es reparar en que la magistratura ya no es sólo instancia de garantía de los derechos, sino también mecanismo externo de control de los poderes públicos con el parámetro de la legalidad. Y es esta faceta de la realidad práctica del ejercicio de su función la que va resaltando social y políticamente su incidencia y su posición en el sistema.

V.

Partiendo de estos parámetros, muy pocos negarían a estas alturas de la historia la intrínseca "politicidad" de la función judicial. Su inserción en el sistema de división y de contrapesos entre los poderes y la legitimación que de ello se deriva, no puede ser concebida sino en clave política, así como políticas son también las consecuencias que el ejercicio de la función (interpretación/creación, efectos sobre la orientación política general) producen sobre el sistema: toda aplicación, toda interpretación de las leyes suponen implícitamente, por el grado de apertura que la relativa densidad de las normas permiten, una elección que es política lato sensu entendida; de ahí que las actuaciones y resoluciones de la magistratura en materias de cierta transcendencia política "focalicen" la atención de los medios y de la opinión pública. "El juez -ha dicho Massimo Morisi- en el cumplimiento de sus propias tareas institucionales, está llamado a compartir con la clase política la distribución de los valores y de los recursos que alimentan el conflicto, la convivencia y la fragmentación de una colectividad históricamente dada". 
Pero dicho y afirmado esto, debe subrayarse que la función del juez no es ni puede ser política en un Estado de Derecho, en el sentido de estar contaminada de parcialidad por deliberada orientación ideológica o programática, esto es, por ser partidista, arbitrista o, sencillamente, creacionista, precisamente porque las actuaciones y decisiones judiciales están en una relación de exclusiva y absoluta sumisión jurídica a la Constitución y a la ley. En esto radica la independencia de los jueces, garante de la imparcialidad. La legitimidad del juez (que no es de origen en nuestro sistema) se asienta aquí, en su imparcialidad, esto es, en su neutralidad o terciedad, y su operacionalización puede jurídica y públicamente contrastarse por sus modos de actuación y, sobre todo, de argumentación y fundamentación: estos sólo pueden ser jurídicos, nunca políticos. En palabras de Martin Kriele, la frontera entre política y Derecho no es la que separa la decisión de la deducción metódica, sino la que distingue los modos de fundamentación y argumentación de las decisiones $y$ diferencia entre las decisiones políticamente fundamentadas y aquellas que lo son jurídicamente. Desde esta óptica, es obvio que no existe un requerimiento de imposible apoliticismo a los jueces, así como que estos son, en el plano de las convicciones políticas, enteramente iguales a cualquier otro ciudadano, aunque la Constitución les prohíba, mientras se encuentren en activo, pertenecer a partidos políticos o a sindicatos, lo que esta más bien dirigido, como dejó dicho De Otto, a mantener una imagen de neutralidad $y$ un apartamiento de un medio conflictivo susceptible de producir apariencias de deslegitimación en el ejercicio de la jurisdicción. Ahora bien, todo esto no significa que las actuaciones de los jueces no estén inspiradas, con mayor o menor respeto o alejamiento de los requerimientos de su función constitucionalmente definidos, por una cierta concepción general sobre la vida y la sociedad $y$, en su seno, por una cierta apreciación, siquiera sea implícita, de un modelo de juez.

\section{VI.}

Refiriéndose a la judicatura italiana, Renato Tréves descubría en ella tres tendencias valorativas que son también tres concepciones diferentes sobre la sociedad y el papel en ella de los jueces: la uestructural funcionalista", conservadora-liberal y tradicional; la "conflictualista dicotómica de tipo marxista», radical e innovadora, partidaria del "uso alternativo del Derecho", y la "conflictualista pluralista", crítica, reformadora y humanista, abierta al cambio social y a las posibilidades del caso concreto. Pues bien, si aplicáramos estos "tipos ideales" al caso 
español, no creo que fuera demasiado atrevido ni descaminado decir que nuestra judicatura responde mayoritariamente en sus modos de actuación, en líneas generales, al modelo "estructural funcionalista", con muy escasas y episódicas manifestaciones, hoy casi agotadas, de la llamada línea "conflictualista dicotómica" y con un creciente y apreciable peso del tipo ideal "conflictualista pluralista", que es precisamente el que mejor se corresponde con los fines y valores constitucionalmente proclamados y con la forma particular de Estado social y democrático de Derecho en el que la nación española se constituye.

Esta línea es representativa de un modelo de juez que ha de ser formado para poder percibir en toda su complejidad la realidad social de su tiempo y, en definitiva, para ser capaz de actuar con independencia plena y consciente de su papel en la democracia avanzada que nuestra Constitución propugna, como garante de la libertad, de la igualdad $y$ de los derechos y libertades fundamentales que las aseguran; esto es, un juez jurista práctico, respetuoso de la Constitución y de la ley, pero ajeno a un estéril y rígido positivismo. Un juez inserto en la sociedad, esto es, "fuera de su jurídico aislamienton como dice Elías Díaz, crítico, atento al Derecho y no sólo a la ley. Esta línea, subrayaba Tréves mostrándose partidario de ella, pretende en definitiva «integrar las exigencias del liberalismo tuteladas por la doctrina del Estado de Derecho y de la división de poderes con las exigencias de la democracia más favorable y sensible hacia las transformaciones económicas y sociales".

No obstante, no puede decirse que los sistemas de acceso y formativo de los jueces hayan propiciado el desarrollo de esta línea en la judicatura española; ni las condiciones estructurales de la Administración de Justicia, deficitaria, en buena medida obsoleta y menesterosa en tantos aspectos de reforma, de una gran reforma, ni los sistemas de formación y acceso a la carrera de los jueces, han permitido que en su conjunto puedan estar estos imbuidos en plenitud de la función que la Constitución les encomienda. La judicatura española se ha rejuvenecido profundamente en los últimos años y un buen porcentaje de mujeres han accedido a una función tradicionalmente reservada a los varones (la sexta parte), pero el crecimiento súbito de las plantillas ha llevado a la pérdida de rendimiento global (sigue habiendo pocos jueces y muchos abogados) y en condiciones de escasa calidad debido a una incorporación acelerada de personal no del todo preparado. José Juan Toharia, que ha estudiado en detalle estas cuestiones, ha detectado la autoconciencia que los jueces tienen de este problema, siendo abrumadora mayoría los que piensan que los nuevos jueces no llegan suficientemente preparados a sus destinos, sintiéndose a sí mismos, 
en conjunto, mal formados, sin que el Centro de Estudios Judiciales acabe de desempeñar adecuadamente su misión formativa una vez superada la oposición.

Por estas razones no es todavía el juez "conflictualista pluralista" el arquetipo del juez español. Más bien podemos describir que en el seno de la judicatura, sobre el fondo predominante de la línea "estructural-funcionalista", se ha gestado con el cambio generacional y con el paso de estos años de democracia una vanguardia de jueces, sobre todo en el ámbito penal, muy preparados, en buena medida autodidactas tras su paso por las facultades de Derecho y la realización de la oposición, fuertemente imbuidos de la excelencia de su función, celosos de su independencia y dispuestos a actuar con sensibilidad en relación a delitos sociales, económicos, ecológicos, etc...

$Y$ es el caso también que durante la primera década del régimen constitucional, el Estado de partidos había venido desarrollando, con desigual pero creciente intensidad, los fenómenos habitualmente a él asociados de colonización de la sociedad y de corrupción -según los términos empleados por García de Enterria-; pero éstos aún no eran muy visibles y no podía percibirse la entera magnitud del fenómeno. Por esa razón, el debate sobre justicia y política seguía centrándose todavía en torno al pretendido conservadurismo de los jueces, a las carencias de la Administración de Justicia y su dependencia del ejecutivo $y$, sobre todo, en el plano más intelectual y académico, en torno a las posibilidades y legitimidad del "uso alternativo del Derecho" en un Estado con una autoproclamada querencia social en sentido fuerte. Pero cuando eclosiona a comienzos de la presente década el fenómeno de la corrupción y surge a la superficie lo que se percibe como la punta del iceberg, algunos de aquellos jueces y fiscales, muy pocos por obvias razones de organización de la Justicia, receptivos al generalizado sentimiento social difuso de una intensa y devastadora pérdida de legitimidad (de uso, de ejercicio) de la democracia de partidos, animados por el ejemplo italiano y espoleados hasta el límite por los medios de comunicación, han llegado a considerar legítimo, con más o menos corrección en sus modos de proceder, que su función exige actuar frente a los males de la democracia y hacer justicia exigiendo el cumplimiento igual de la ley para todos, plantando cara si ello es necesario a los ámbitos otrora inmunes del poder.

Desde un cierto ethos de recelo sistemático y de hostilidad frente al poder, especialmente frente a las capas altas de la Administración y de los partidos y frente a personajes influyentes identificados como vinculados a aquellas (aunque no siempre necesariamente frente a los po- 
derosos), y desde una posición personal, ¿por qué no decirlo?, megalothymica, procuran mantener una comunicación estrecha y frecuente con la sociedad civil y política y se constituyen a sí mismos, con su trabajo sobre temas de gran notoriedad pública (corrupción, narcotráfico, terrorismo, violaciones de los derechos humanos..., en dimensión internacional), en centros de referencia y, a veces, incluso en líderes de opinión, pronunciando conferencias por doquier, escribiendo libros, firmando manifiestos y participando intensamente en los medios de comunicación concediendo entrevistas, haciendo declaraciones y comunicados, publicando artículos...; $e$ incluso ha habido algún juez habitual en tertulias radiofónicas en las que diariamente se comentan y critican los acontecimientos politicos y se emiten juicios de todo orden sobre los actores políticos, las instituciones y los poderes del Estado a propósito de asuntos sub iudice vinculados a la política y con sumarios declarados secretos. En algunos casos, con inmediato camino de ida $y$ vuelta, sin solución de continuidad, como es bien conocido, ha habido quienes han dado el salto a la política, si bien se ha tratado de un fenómeno minoritario y escasamente dilatado en el tiempo, con resultados realmente funestos, pero bien ilustrativo en el orden simbólico.

Se completa así el camino de la evolución de la tipología del juez español descrita por Tomás y Valiente, aunque sólo sea válida para un muy reducido grupo de jueces: «Del juez aplicador de la ley obediente sólo a su letra se pasa al juez consciente de su papel como poder del Estado, ya que en cada uno de ellos reside el poder de juzgar $y$ de hacer ejecutar lo juzgado. Del juez aislado y callado, al juez asociado y proclive a hablar cuando se le pone un micrófono delante. Del juez discreto, al juez aquejado de incontinencia verbal. Del juez prudente, al juez activista y de éste al juez políticon. Tan político, cabría decir, que en este enrarecido ambiente y con estas tan difusas e incontroladas querencias, no es extraño que acabe viéndose involucrado, por activa o por pasiva, en turbios procesos de maquinación para provocar cambios políticos en una determinada dirección, como recientemente ha sucedido.

Naturalmente, el que las cosas sean asi no es el producto azaroso de la personalidad de unos concretos jueces. La cuestión es que se dan también circunstancias estructurales y de organización de la función de juzgar que abonan estas disfunciones. De especial magnitud, entre otras, es, por supuesto, la atribución de la instrucción de las causas penales a los jueces y no al ministerio fiscal. Algunos jueces a los que aqui venimos refiréndonos, que son los especialmente relevantes por los asuntos que han de conocer, esto es, los de la Audiencia Nacional, han asumido su papel, con excepciones, mimetizando los po- 
deres autónomos de la fiscalía italiana (Mani Pulite), como brazo acusador de la sociedad, defensor efectivo de la democracia junto con los medios de comunicación, sin tener que dar cuenta a nadie -en aras de la independencia- de sus actuaciones, cuando en realidad debieran estar circunscritos a la tarea de juzgar y hacer ejecutar lo juzgado como elemento neutral supra partes que garantiza la efectividad del ordenamiento. Si esta circunstancia se combina con la huida de los políticos de la aceptación de la responsabilidad política hasta que no se declare la penal, el riesgo de que tales jueces asuman paladinamente una función que no les corresponde es todavía mayor y la ceremonia de la confusión para el sistema político está servida.

VII.

Este tipo de juez, el «juez estrella" o "juez político" es en consecuencia, como resulta notorio y vengo sosteniendo, la gran excepción y la gran novedad; en parte es el resultado de procesos de crisis de la democracia y epifenómeno inevitable de lo que Alain Minc ha llamado la "nueva democracia de la opinión pública», en la que la disolución de los viejos mitos, en particular el del interés del Estado como encarnación del interés general, y la "borrachera democrática" subsiguiente, hacen aparecer al Derecho y al juez como únicas instancias fiables y definitivas de la resolución de los conflictos, ya sean sociales, institucionales, políticos o morales, por más que esta perspectiva resulte paradójica si se tiene en cuenta, a su vez, el formidable déficit de legitimidad que la justicia tiene entre la opinión pública como consecuencia de sus arcaismos y deficiencias. Hoy, en suma, se desconfía del Estado constitucional como estructura y se proclama la necesidad de un mayor protagonismo de la sociedad civil, con lo que se produce una transferencia de poder del Estado a la sociedad y una mayor capacidad de influencia de los poderes privados; pero se reclama paralela y paradójicamente un fortalecimiento del Estado y del Derecho Constitucional como sistema de garantías (Pedro de Vega) y, por lo tanto, se realimenta el recurso a la magistratura, cuya importancia política aumenta considerablemente. Todo un proceso de simbolización confluye en esta aceleración de la expansión jurídica donde todo y todo el mundo debe ser justiciable. Como ha dicho Antoine Garapon, «la promoción contemporánea del juez procede menos de una elección deliberada que de una reacción de defensa ante un cuádruple hundimiento: político, simbólico, psíquico y normativo...El juez aparece como un recurso contra la implosión de las sociedades democráticas que no llegan ya a controlar de otra manera la 
complejidad y la diversidad que engendran... Ante la descomposición de lo político, es al juez a quien se le pide la salvación. Los jueces son los últimos ocupantes de una función de autoridad -clerical o paternalde la que han desertado sus antiguos titulares".

En este nuevo escenario, la judicialización acaba por imponer su versión penal a toda relación, ya sea política, administrativa o social y nos encontramos así, finalmente, con un tipo de juez que en el imaginario colectivo aparece como muy activo, en lucha desigual frente al poder, empleado frente a males universales, capaz por su tenacidad para hacer justicia frente a los poderosos $y$, por ello, si es necesario, capaz de hacer la ley al caso concreto. A pesar de su excepcionalidad, la notoriedad e importancia de los asuntos que instruyen concentran, por la intermediación de los intereses propios (y no sólo de orden económico) de los medios de comunicación de masas, la atención del conjunto social, produciendo una apariencia, sobre el fondo de la judicialización de la vida pública y de la búsqueda de una cierta moralización de la misma, de una completa politización de la justicia. Los medios, a su vez, con la cobertura legitimadora que les presta su función de asegurar la máxima transparencia, trasladan el escenario del proceso a la opinión -pese a la inevitable conculcación de la presunción de inocencia de los imputados- $y$ alimentan en los ciudadanos una evidentemente falsa sensación de democracia directa que no les permiten las instituciones de la democracia representativa.

Buena parte de la responsabilidad por esta situación no es ni de tales jueces, ni de los medios, sino también de los políticos. La propia dinámica inercial de estos fenómenos induce a que desde las propias instancias políticas se renuncie progresivamente a procedimientos de control y responsabilidad propiamente políticos, que se vuelven inanes de cara a la opinión pública, y cada vez más se residencien asuntos de neta confrontación y oposición política en los tribunales, bien sea ante el Tribunal Constitucional, bien ante la jurisdicción ordinaria. Hay sin duda, como ha manifestado Miguel Sánchez Morón, un preocupante repliegue de los políticos electos, una cada vez mayor interferencia e importancia en la política de otros agentes sociales (grupos económicos, medios de comunicación, personajes encumbrados por estos mismos medios) y una difusa identificación de la democracia con una especie, más que de Estado de Derecho, de «Estado de la justicia judicial», donde "el juez parece adquirir una legitimación superior a la de los políticos electos", al fin y al cabo presentados y en buena medida percibidos como urepresentantes de un sistema corrupto, opaco y partidocrático». 
Lo nuevo es, en consecuencia, que la escena política aparece, bajo los focos de los medios de comunicación centrada en el permanente quehacer de esa nueva figura del juez "justiciero" que saca a la justicia de su mudez y se lanza al fragor de la lucha, interfiriendo en la política y generando un considerable sesgo y desquiciamiento del equilibrio institucional, con retraimiento e incapacidad de los poderes políticos, que se ven permanentemente a remolque de la opinión publicada y de las instrucciones de los sumarios en curso y sus recurrentes filtraciones. Todo ello conduce a la emisión de un juicio negativo, condenatorio, contra este tipo de juez "político", expresivo de una especie de democrática "irritación" ante la subversión conceptual y de facto que aparentemente provoca en el funcionamiento del sistema democrático, alterando la división de los poderes.

VIII.

No obstante lo certero en buena medida de esta apreciación, no creo que debamos dejarnos engañar por las apariencias. La situación debe ser vista en una dimensión más real, más objetiva y compleja, con independencia de los planos exclusivamente individuales o de casta. El juez "estrella» es un epifenómeno y una excepción surgida en una cultura jurídica en la que la magistratura no ha tenido una sostenida y asentada tradición de independencia. Por ello va camino de convertirse, como desde otra perspectiva sucediera con el juez ultraconservador de comienzos de los ochenta, en el estereotipo de los noventa. Es tan sólo, como la fiebre, un exagerado síntoma de los cambios que se están produciendo en el Estado democrático; un síntoma que apunta todavia hacia lo desconocido y lo desconocido desconcierta, asusta e irrita. Verdaderamente la cuestión es no alcanzar a atisbar con claridad en qué dirección caminamos.

El problema, pues, no está primariamente ni en los «jueces estrella" ni en el inexistente "gobierno de los jueces", pues éstos no pueden actuar de oficio, ni bajo programa, ni perseguir desde su posición los bienes inciertos de la política, ni definir el bien general, ni la razón de Estado, ni adoptar decisiones políticas, ni argumentar políticamente. La Constitución y la ley se lo prohíben y pueden por ello ser, a su vez, controladas sus actuaciones y resoluciones, y no sólo a la luz de la opinión, sino también jurídicamente. En todo caso, sólo pueden perseguir el bien jurídico de investigar, controlar y eventualmente juzgar actos de los ciudadanos y de los poderes públicos bajo el imperio de la ley, esto es, según la certeza del Derecho. 
La cuestión radica en que, en una democracia avanzada, el control jurisdiccional es el punto nodal de la normatividad $y$, por ende, de la constitucionalidad $y$ de la legalidad $y$, en definitiva, la única garantía de la justicia igual, así como la última y decisiva fase de la exigencia de responsabilidad. Si además, ésta no ha funcionado políticamente en otros niveles (por haberse supeditado a la declaración de la penal, o por otros motivos) cuando ello no sólo es posible sino conveniente y deseable, fundamentalmente en el Parlamento, y la clase politica recurre masivamente a los jueces y al Derecho penal, no es posible atribuir a estos, sin equivocarse, la búsqueda de un ilegítimo protagonismo político y considerarlos la causa fundamental productora del desequilibrio institucional existente. Son los procesos objetivos de deslegitimación hoy operantes en el Estado democrático los que han llevado, por una parte, a la clase política a esa permanente apelación a lo jurídico y por otro, a las fuerzas políticas a crispar el debate y a residenciarlo en la última sede en las que los conflictos pueden residenciarse: en los juzgados y tribunales.

El ya no tan reciente afloramiento de una corrupción de grandes dimensiones y el blanqueo de dinero a ella asociado, la criminalidad organizada transnacionalmente con un complejísimo despliegue tecnológico, la guerra sucia contraterrorista, etc..., y la exigencia íneludible de que el Estado democrático y, en su nombre, el Estado-juez, el poder judicial, los jueces, actúen, investiguen y apliquen la ley con rigor y de manera igual para todos, ha abierto también un boquete de considerables dimensiones en la tradicional opacidad del poder; $y$ ni el poder político ni el poder económico pueden permitirse desde su propia lógica de actuación que este proceso llegue a sus últimas consecuencias. De ahí también la fortaleza de la oposición a las instrucciones de los sumarios relativos a estas causas, que contribuye a su cada vez mayor complejidad, a la dilatación sine die en su tramitación y a la poco deseable realimentación de la función política del juez, obligado por muy estrechos vericuetos llenos de obstáculos a la búsqueda universal de datos en los que sustentar las imputaciones.

En este escenario, la clase política corre el riesgo de deslegitimarse cada vez más $y$ algunos sectores judiciales también, por impregnarse inevitablemente su actuación, bien por intereses propios, bien por errores o por la interferencia de los medios de comunicación y sus "procesos paralelos", o por una mezcla de todas estas cosas, de ciertos modos políticos de obrar, lo cual acabaría siendo muy peligroso para la Justicia en su conjunto. El corazón mismo del Estado democrático se ve así afectado pero, paradójicamente, el conocimiento 
pleno, el desvelamiento de lo que puede procurarle crisis y deslegitimación, es lo único que puede salvarlo y relegitimarlo. Hemos de pensar que siempre llegan momentos para la imperfecta democracia (Raymond Aron) en que ésta necesita convertirse en una máquina de bombear basura y que cuanta más basura aparezca en la superficie, más ejercicio se está haciendo de ella. Lo inquietante sería no percibir que lo que está en crisis no es la democracia misma como sistema, sino una determinada situación política que puede superarse. Una situación en la que casi todos los días -como nos recordaba no hace mucho Manuel Vicent- los mass media han venido aflorando a la superficie, efectivamente, toneladas de basura sobre fabulosas corrupciones, conspiraciones y espionajes que desafían a cualquier ficción, actuaciones en las cloacas o en los confines del Estado de Derecho, tráficos de influencias $y$ otros affaires sensibles del mundo de las finanzas, de la política y de la comunicación.

Así las cosas, la razón de los gobernantes o, mejor, la razón de los poderosos, no puede desplazar a la urazón de Estado"; porque hoy la razón de Estado consiste en la relegitimación de la democracia, en la devolución de su sentido profundo al ciudadano, y para ello es imprescindiblemente necesario que afloren a la superficie todos sus demonios para poder conjurarlos, eso sí, con la razón del Estado de Derecho. La confianza del pueblo es el valor básico de la democracia y por ello el sistema institucional no puede admitir que ese depósito se agote. La conclusión no puede ser otra sino la de que dejemos actuar a los jueces. No confundamos los nombres de los protagonistas, ni sus formas de actuación, por erradas que puedan ser manifiestamente en algunos casos, con la cosa. Visto el panorama desde esta óptica los llamados jueces estrella podrán ser, efectivamente, jueces políticos en cierto sentido, pero lo relevante en relación a la cuestión de fondo es que los asuntos que instruyen son descarnadamente políticos y se utilizan políticamente por todos los actores del teatro de la política, precisamente por sus efectos políticos. Las consecuencias de sus instrucciones y resoluciones son inmediatamente políticas. Incluso pertenece a la índole de lo más rabiosamente político que sus modos de actuar se vean interferidos y fuertemente condicionados por el uso torticero de los mecanismos procesales, por la política misma y, de manera especialmente intensa por su importancia cualitativa, por los déficits de la cooperación judicial internacional, estratégicamente administrada por los gobiernos y también por razones políticas. $Y$ no son los jueces estrella quienes han judicializado la política, sino buena parte de la política misma, su núcleo duro, por los fenómenos antes apuntados, la que se ha mudado a las páginas, a los micrófonos, a las pantallas de los medios de comunica- 
ción y a las antesalas de los palacios de justicia. El fenómeno es casi universal, aunque especialmente europeo, pero ¿acaso en la actualidad hay ya algún fenómeno que escape a la "mundialización" acelerada de los procesos económicos, sociales, políticos e ideológicos? En la democracia avanzada actual, evitar tanto el activismo judicial como la judicialización excesiva, especialmente la política, exige, de acuerdo con el planteamiento de Garapon -fino analista de estos fenómenos- revalorizar la imparcialidad, rehabilitar la ética, recuperar la representatividad, responsabilizar a los actores de la democracia, ciudadanos, políticos, jueces y periodistas y recuperar la idea y el sentido del interés general.

\section{REFERENCIAS BIBLIOGRÁFICAS}

AndRÉs laÁñez, Perfecto (Ed.): Corrupción y Estado de Derecho. El papel de la jurisdicción. Madrid, Trotta, 1996.

AndRÉs Ibáñez, Perfecto y Movilla, Claudio: El Poder Judicial. Madrid, Tecnos, 1986.

Aparicio Pérez, Miguel Ángel: El status del Poder Judicial en el constitucionalismo español (1808-1936). Publicacions Universitat de Barcelona, 1995.

- "Justicia y jueces en la Constitución española de 1978», Ponencia presentada en la II Conferencia de Presidentes de Cortes y Tribunales Superiores de Justicia de lberoamérica, Portugal y España, celebrada en Madrid el 4 de octubre de 1993, en la sede del Consejo General del Poder Judicial (He consultado el ejemplar inédito por gentileza de su autor).

BaCHOF, Otto: Jueces y Constitución. Madrid, Cuadernos Cívitas, 1985.

Cano Bueso, Juan: La política judicial del régimen de Franco (1936-1945). Madrid, Ministerio de Justicia, 1985.

- "Notas sobre la "Administración" de Justicia en el Totalitario. Especial referencia a la España de Franco (1936-1945)". Anuario de Derecho Públiço y Estudios Políticos, n. ${ }^{\circ}$, Monográfico sobre el Poder Judicial, Granada, 1988, págs. 5-21.

Diez-Picazo Giménez, Luís M.a: Régimen constitucional del Poder Judicial. Madrid, Cuadernos Cívitas, 1991.

- «Notas de derecho comparado sobre la independencia judicial». Revista Española de Derecho Constitucional, n. ${ }^{\circ} 34,1992$, págs., 19-39.

Garapon, Antoine: Juez y democracia. Una reflexión muy actual. Barcelona, Flor del Viento Ediciones, 1997.

Garcia de EnTerRIA, Eduardo: Democracia, jueces y control de la Administración. Madrid, Cívitas, 1995.

García Morillo, Joaquín: «EI Parlamento en la era global». Cuadernos de Derecho Público, n. ${ }^{\circ}$ 1, mayo-agosto, 1997, págs. 77-100.

Garrorena Morales, Ángel: Representación política y Constitución democrática. (Epílogo de M. Aragón Reyes) Madrid, Cuadernos Cívitas, 1991. 
Huertas Contreras, Marcelo: El poder judicial en la Constitución española. Servicio de Publicaciones de la Universidad de Granada, 1995.

LA Justicia en España. Número monográfico (7) de la revista Temas para el Debate, junio de 1995.

LOPEz AgUILAR, Juan Fernando: La justicia y sus problemas en la Constitución. Madrid, Tecnos, 1996.

López GuerRa, Luis: "La legitimidad democrática del juez". Cuadernos de Derecho Público, n. ${ }^{\circ} 1$, mayo-agosto, 1997, págs. 43-76.

Lucas -Murillo de la Cueva, Pablo: “El gobierno del Poder Judicial: los modelos y el caso español». Revista de las Cortes Generales, n. ${ }^{\circ} 35,1995$, págs. 167-239.

Minc, Alain: La borrachera democrática (El nuevo poder de la opinión pública). Madrid, Ediciones Temas de Hoy, 1995.

Mohedano, José M. ${ }^{a}$ : "Los jueces, nuevos actores de la política». Sistema, n. 130) 1996.

Montero Aroca, Juan: Independencia y responsabilidad del Juez. Madrid, Cuadernos Cívitas, 1990.

- "Poder judicial y Administración de Justicia en la Constitución y en la práctica». En E. Álvarez Conde (ed.) Diez Años de Régimen Constitucional Español, Madrid, Tecnos1989.

MoRISI, Massimo: "Jurisdicción y política: Viejas preguntas al hilo del caso italiano". Revista de estudios Políticos, . $^{\circ} 85,1994$, págs. 9-36.

Ollero TASSARA, Andrés: Interpretación del Derecho y positivismo legalista. Madrid, Edersa, 1982.

- "Juzgar o decidir: el sentido de la función judicial», Poder Judicial, n. ${ }^{\circ} 32$, diciembre, 1993, págs. 123-139.

De Otto y PARdo, Ignacio: Estudios sobre el Poder Judicial. Madrid, Publicaciones del Ministerio de Justicia, 1989.

El Poder Judicial en el conjunto de los Poderes del Estado y de la Sociedad. Número especial XI, monográfico, de la Revista Poder Judicial. Consejo General del Poder Judicial, Madrid, 1986.

Requejo Pagés, Juan Luís: Jurisdicción e independencia judicial. Madrid, Centro de Estudios Constitucionales, 1989.

Revenga SÁnChez, Miguel: "Función jurisdiccional y control político». Revista Española de Derecho Constitucional, n. ${ }^{\circ} 29,1990$, págs. 117-142.

RIGHETIINı, Stella: "La politicizzazione di un potere neutrale. Magistratura e crisi italiana". Rivista Italiana di Scienza Politica, Anno XXXV, núm. 2, agosto, 1995, págs. 227-265.

Robert, Denis: La justicia o el caos. Barcelona, Muchnik Editores, S.A., 1996.

Rulz-Rıco, Juan José: "El juez español, Un problema abierto a la investigación». Anuario de Derecho Público y Estudios Políticos, n.ำ 1, Monográfico sobre El Poder Judicial, Granada, 1988, págs., 135-153.

SAAVEDRA López, Modesto: «Poder judicial, interpretación jurídica y criterios de legitimidad". Anuario de Derecho Público y Estudios Políticos, n. ${ }^{\circ} 1, \mathrm{Mo}-$ nográfico sobre El Poder Judicial. Granada, 1988, págs. 39- 61. 
Santolaya Machetti, Pablo: «El control de los secretos de Estado; la experiencia en derecho comparado". Poder Judicial, n. ${ }^{\circ} 40$, octubre-diciembre, 1995, págs. 57-83.

Simón, Dieter: La independencia del juez. Barcelona, Ariel, 1985.

TohaRIA, José Juan: Pleitos tengas... Una introducción a la cultura legal española. Madrid, Centro de Investigaciones Sociológicas, 1979.

- "La Administración de Justicia en España». En J. Tussell, E. Lamo de Espinosa y E. Pardo (Eds.): Entre dos siglos, Reflexiones sobre la democracia española. Madrid, Alianza Editorial/Fundación Ortega y Gasset, 1996, págs. 295-313.

Tomás y VALIENTE, Francisco: A orillas del Estado. Barcelona, Círculo de Lectores, 1996.

Tréves, Renato: Introduzione alla Sociologia del Diritto. Torino, Giulio Einaudi Editore, 1977.

De Vega García, Pedro: Seminario de profesores sobre "La crisis del Estado". Universidad de Granada, 31 de enero de 1997 (texto inédito).

Vera PADIAL, Maria Mercedes: «EI perfil social e ideológico de la élite jurídica española (Una reflexión inicial)". Anuario de Derecho Público y Estudios Politi$\cos , \mathrm{n}^{\circ}$ 1, Monográfico sobre El Poder Judicial, Granada, 1988, págs. 187-205.

Woodhouse, Diana: "Politicians and the Judges: A Conflict of Interest". Parliamentary Affairs (A Journal of Comparative Politics). Vol. 49, n. 3 , July, 1996.

\section{ARTÍCULOS DE PRENSA SELECCIONADOS}

ANDRÉs IBAÑNEZ, Perfecto: "¿La política sofocada por el derecho?». Diario el País, Domingo, 27 de octubre de 1996.

- «El tablero de la justicia». El País, jueves, 28 de noviembre de 1996.

Díz-PICAzo Luís M.a: "Secretos oficiales: dos nuevas propuestas», El País, miércoles, 16 de octubre de 1996.

"Los olvidados deberes de la politica". El País, jueves, 31 de octubre de 1996. Movilla Álvarez, Claudio: "Actos políticos y Constitución». Ideal, viernes, 25 de octubre de 1996.

REvenga, Miguel: "Los papeles del CESID" y los "Papeles del Pentágono". El País, lunes, 7 de octubre de 1996.

SÁnchez Morón, Miguel: "Democracia y judicialismo". El País, Miércoles, 2 de octubre de 1996.

Savater, Fernando: "La dignidad del Estado". El País, jueves, 31 de octubre de 1996.

ZAFra Victor, Manuel: "El 'caso GAL' y la razón de Estado». El Correo, Domingo, 22 de enero de 1995.

- "Actualidad de Montesquieu". El Correo, Viernes, 5 de mayo de 1995.

- "Entre la corrupción y el moralismo». El Correo, Sábado, 27 de julio de 1996.

— «QQuien desclasifica?». Ideal, jueves, 17 de octubre de 1966. 